\title{
Hemorheological and metabolic
} consequences of renal ischemia-reperfusion and their modulation by N,N-dimethyltryptamine on a rat model

Katalin Peto ${ }^{\mathrm{a}}$, Norbert Nemeth ${ }^{\mathrm{a}, *}$, Anita Mester ${ }^{\mathrm{a}}$, Zsuzsanna Magyara ${ }^{\mathrm{a}}$, Souleiman Ghanem ${ }^{\mathrm{a}}$, Viktoria Somogyi ${ }^{\mathrm{a}}$, Bence Tanczos ${ }^{\mathrm{a}}$, Adam Deak ${ }^{\mathrm{a}}$, Laszlo Bidiga ${ }^{\mathrm{b}}$, Ede Frecska ${ }^{\mathrm{c}, 1}$ and Balazs Nemes ${ }^{\mathrm{d}, 1}$

${ }^{a}$ Department of Operative Techniques and Surgical Research, Institute of Surgery, Faculty of Medicine, University of Debrecen, Debrecen, Hungary

${ }^{\mathrm{b}}$ Department of Pathology, Faculty of Medicine, University of Debrecen, Debrecen, Hungary

${ }^{\mathrm{c}}$ Department of Psychiatry, Faculty of Medicine, University of Debrecen, Debrecen, Hungary

${ }^{\mathrm{d}}$ Division of Organ Transplantation, Institute of Surgery, Faculty of Medicine,

University of Debrecen, Debrecen, Hungary

\begin{abstract}
.
BACKGROUND: Micro-rheological relations of renal ischemia-reperfusion (I/R) have not been completely elucidated yet. Concerning anti-inflammatory agents, it is supposed that sigma-1 receptor agonist N,N-dimethyl-tryptamin (DMT) can be useful to reduce I/R injury.

OBJECTIVE: To investigate the micro-rheological and metabolic parameters, and the effects of DMT in renal I/R in rats. METHODS: In anesthetized rats from median laparotomy both kidneys were exposed. In Control group $(n=6)$ no other intervention happened. In I/R group $(n=10)$ the right renal vessels were ligated and after 60 minutes the organ was removed. The left renal vessels were clamped for 60 minutes followed by 120-minute reperfusion. In I/R+DMT group $(n=10)$ DMT was administered 15 minutes before the ischemia. Blood samples were taken before/after ischemia and during the reperfusion for testing hematological, metabolic parameters, erythrocyte deformability and aggregation.

RESULTS: Lactate concentration significantly increased and accompanied with decreased blood pH. Enhanced erythrocyte aggregation and impaired deformability were observed from the 30th minute of reperfusion. In I/R+DMT group we found diminished changes compared to the I/R group (lactate, $\mathrm{pH}$, electrolytes, red blood cell deformability and aggregation).

CONCLUSIONS: Metabolic and micro-rheological parameters impair during renal I/R. DMT could reduce but not completely prevent the changes in this rat model.
\end{abstract}

Keywords: Kidney, ischemia-reperfusion, hemorheology, N, N-dimethyl-tryptamine

\section{Introduction}

Renal ischemia-reperfusion (I/R) is characterized by cessation of blood supply followed by restoration of the circulation and re-oxygenation, leading to alterations in morphology and function, depending on the duration of the ischemia and the circumstances of reperfusion. It may occur in a broad spectrum of clinical settings including surgery, trauma, dehydration or sepsis [1]. It is inevitable in renal

\footnotetext{
${ }^{1}$ These authors contributed equally to the work.

${ }^{*}$ Corresponding author: Norbert Nemeth MD, PhD, DSc, Department of Operative Techniques and Surgical Research, Institute of Surgery, Faculty of Medicine, University of Debrecen, H-4032 Debrecen, Nagyerdei krt. 98., Hungary, Tel./Fax: +36 52416 915; E-mail: nemeth@ med.unideb.hu.
} 
transplantation and may be responsible for acute kidney injury, delayed graft function, high risk of acute rejection and chronic graft dysfunction $[2,3]$.

The kidney is particularly sensitive to $I / R$ because of its vascular anatomy and high rate of metabolism. Many factors are involved in the pathophysiology of the ischemia-reperfusion injury [2, 4-9]. Tissue damage is determined primarily by the magnitude and duration of the ischemia but further damage develops during the subsequent reperfusion $[5,7,8]$. During ischemia there is a lack of oxygen and nutrients, which leads to a decrease in oxidative metabolism, accumulation of waste products and depletion of ATP. Anaerobe metabolism and lactate accumulation results in intracellular $\mathrm{pH}$ decrease. When reperfusion is established, in spite of reoxygenization and return to aerobe metabolism further damage occurs, mainly due to the excessive production of reactive oxygen species, but inflammatory response is also implicated $[5,8,10]$. These mechanisms lead to severe cellular injury and contribute to early graft rejection and to the remote injury of other organs [11].

Regarding the micro-rheological parameters, I/R may have an impact on red blood cell aggregation and deformability due to metabolic changes, free radical reactions and acute phase reactions [12-14]. Micro-rheological parameters are highly important in determining microcirculation $[13,15-17]$, therefore their investigation may provide important information about the pathomechanism of renal ischemia-reperfusion injury.

Several methods exist to prevent or reduce I/R injury, acting at different phases and influencing various pathways during the process $[18,19]$. N,N-dimethyl-tryptamine (DMT) is a powerful psychedelic drug. In 2014 Szabó et al. demonstrated the immune-modulator potential of DMT and 5-MeO-DMT through the sigma-1 receptor of human immune cells. Based on their results, the immunemodulator activity of DMT may have a significant anti-inflammatory effect and may contribute to tissue regeneration [20].

In our study we wished to investigate whether renal ischemia-reperfusion may cause deterioration in metabolic and micro-rheological parameters. We hypothesized that administration of DMT can be protective against I/R-induced alterations.

\section{Materials and methods}

\subsection{Experimental animals and study design}

The experiments were approved and registered by the University of Debrecen Committee of Animal Welfare (permission Nr.: 20/2011. UDCAW), in accordance with national (Hungarian Animal Protection Act, Law XVIII/1998) and EU regulations (Directive 2010/63/EU).

Twenty-six healthy, male Crl:WI rats (Toxi-Coop Ltd., Hungary; bodyweight: $343.3 \pm 29.5 \mathrm{~g}$ ) were involved in the study. Only males were used to eliminate potential gender variability. The rats were housed in standard cages in groups of 2-3, on a 12-hour light/dark cycle. Rats were fed with standard rat chow diet and allowed access to water ad libitum.

The animals were randomly divided into three experimental groups: control $(\mathrm{C}, n=6)$, ischemiareperfusion (I/R, $n=10)$ and ischemia-reperfusion with DMT treatment $(\mathrm{I} / \mathrm{R}+\mathrm{DMT}, n=10)$ groups. Anesthesia was introduced with intraperitoneal administration of Thiopental $(60 \mathrm{mg} / \mathrm{bwkg})$ with atropine-sulphate $(0.06 \mathrm{mg} / \mathrm{bwkg}$, s.c. $)$.

\subsection{Operative techniques}

The left femoral artery was cannulated (BD Neoflon $\left.{ }^{\mathrm{TM}}, 26 \mathrm{G}\right)$ under operating microscope (Leica Wild M650) for blood samplings. Midline laparotomy was performed and both kidneys were gently 
exposed in all animals. In the Control group there were no other interventions. In the Ischemiareperfusion (I/R) group the right renal artery and vein were exposed and ligated while the left kidney's vessels were atraumatically clamped. After 60-minute ischemia the right kidney was excised for histopathological examinations in parallel to removing the clamps from the left renal vessels and a 120-minute reperfusion period followed. In the treated group (I/R+DMT), 15 minutes before ligating/clamping the renal vessels, N,N-dimethyl-tryptamine (DMT) (permission for usage: OGYÉI/14595-2/2017) was administered (2.95 ml/bwkg, using $2.45 \mathrm{mg} / \mathrm{ml}$ solution and given i.m.), and repeated again 60 minutes later, 15 minutes before the start of the reperfusion.

At the end of the reperfusion period, after the last blood sampling biopsies were taken from the kidney, liver and a jejunum segment for later histological examination and then the animals were euthanized.

\subsection{Sampling protocol}

Before the ischemia (Base), just after clip removal (I-60), at the 30th (R-30), the 60th (R-60) and the 120th (R-120) minute of the reperfusion blood samples $(0.3 \mathrm{ml}$ each time, anticoagulant: $1.5 \mathrm{mg} / \mathrm{ml}$ $\mathrm{K}_{3}$-EDTA) were taken from the cannulated artery. Similar volume of physiological saline solution was administered just after samplings. In the Control group the timing of blood sampling was identical. At the end of the experiments tissue samples were taken from the kidney, the small intestine and the liver for histological examinations and the animals were euthanized.

\subsection{Laboratory measurements}

Hematological parameters were determined by a Sysmex K-4500 automated hematology analyzer (TOA Medical Electronics Corp., Ltd., Japan). In this study red blood cell count (RBC [T/1]), hematocrit (Hct [\%]), haemoglobin (Hgb [g/dl]), mean corpuscular volume (MCV [fl]), mean corpuscular hemoglobin ( $\mathrm{MCH}[\mathrm{pg}]$ ), mean corpuscular hemoglobin concentration (MCHC [g/dl]), white blood cell count (WBC [G/l]) and platelet count (Plt [G/l]) were analyzed.

The acid-base parameters, glucose and electrolytes were tested by an EPOC portable blood analysis device (Alere, USA). Blood $\mathrm{pH}, \mathrm{pO}_{2}[\mathrm{mmHg}], p \mathrm{CO}_{2}$ [mmHg], base excess (BE(ecf) [mmol/l]), lactate $[\mathrm{mmol} / \mathrm{l}]$, bicarbonate $\left(\mathrm{HCO}_{3}{ }^{-}[\mathrm{mmol} / \mathrm{l}]\right)$, glucose $[\mathrm{mmol} / \mathrm{l}], \mathrm{Na}^{+}[\mathrm{mmol} / \mathrm{l}], \mathrm{K}^{+}[\mathrm{mmol} / \mathrm{l}]$ and $\mathrm{Ca}^{2+}$ $[\mathrm{mmol} / \mathrm{l}]$ concentrations were determined. For the measurements approximately $0.1 \mathrm{ml}$ blood sample is required.

Red blood cell deformability was determined by LoRRca MaxSis Osmoscan rotational ektacytometer (Mechatronics BV, The Netherlands). The method is based on the analysis of the laser diffraction pattern of the elongated red blood cells in the function of sheer stress [21]. Polyvinylpyrrolidone (PVP) phosphate buffered saline (PBS) solution was used as high-viscosity suspending media (Sigma-Aldrich Co. USA; PVP-PBS solution viscosity $=27 \mathrm{mPas}$, osmolality $300 \mathrm{mOsmol} / \mathrm{kg}, \mathrm{pH}=7.3$ ). The measurements were carried out at $37^{\circ} \mathrm{C}$. The elongation index values were determined in the function of sheer stress (SS) [Pa]). For comparison EI-SS curves, EI values at $3 \mathrm{~Pa}$, and by Lineweaver-Burk analysis the maximal elongation index $\left(\mathrm{EI}_{\max }\right)$ and the shear stress at half $\mathrm{EI}_{\max }\left(\mathrm{SS}_{1 / 2}[\mathrm{~Pa}]\right)$, and their ratio were used [22].

Red blood cell aggregation was tested by a Myrenne MA-1 erythrocyte aggregometer (Myrenne $\mathrm{GmbH}$, Germany), based on light-transmittance method [21, 23]. Briefly, the blood sample is disaggregated with high shear rate $\left(600 \mathrm{~s}^{-1}\right)$ and then the shear rate drops to 0 (M mode) or $3 \mathrm{~s}^{-1}$ (M1 mode). Aggregation index values at 0 and $3 \mathrm{~s}^{-1}$ shear rates are determined 5 seconds (M $5 \mathrm{~s}$, M1 $5 \mathrm{~s}$ ) or 10 seconds (M $10 \mathrm{~s}$, M1 $10 \mathrm{~s}$ ) after disaggregation. Higher aggregation index values reflect enhanced aggregation [21]. 


\subsection{Statistical analysis}

Data were expressed as means \pm standard deviation (S.D.). For inter-group comparison Student $t$ test or Mann-Whitney rank sum tests, for intra-group comparison one-way and repeated measures ANOVA tests (Dunn's, Bonferroni's or Student-Newman-Keuls method) were applied, depending on the normality of data distribution. $P<0.05$ was considered statistically significant.

\section{Results}

\subsection{Hematological parameters}

Table 1 shows the changes in quantitative and qualitative hematological parameters.

Red blood cell count (RBC [T/l]), haemoglobin (Hgb [g/dl]) and hematocrit (Hct [\%]) slightly decreased in Control group (RBC: $p=0.012$, Hgb: $p=0.002$ and Hct: $p=0.029$ vs. base), while a moderate hemoconcentration was observed by the 120th minute of the reperfusion in I/R (Hgb: $p=0.028$ and Hct: $p=0.05$ vs. Control) and I/R+DMT group (RBC: $p<0.001$ vs. base and Control, Hgb: $p=0.001$ vs. Control and $p=0.009$ vs. I/R, and Hct: $p=0.009$ vs. Control and $p=0.025$ vs. I/R). Mean

Table 1

Changes of quantitative and qualitative haematological parameters in the Control, Ischemia-Reperfusion (I/R) and DMT-treated Ischemia-Reperfusion groups (I/R+DMT) during the 120-minute reperfusion period after 60-minute of kidney ischemia

\begin{tabular}{|c|c|c|c|c|c|c|}
\hline Variable & Group & Base & $\mathrm{I}-60$ & $\mathrm{R}-30$ & $\mathrm{R}-60$ & $\mathrm{R}-120$ \\
\hline \multirow[t]{3}{*}{$\mathrm{RBC}[\mathrm{T} / \mathrm{l}]$} & Control & $7.65 \pm 0.7$ & $7.34 \pm 0.96$ & $7.23 \pm 0.72$ & $7.2 \pm 0.84$ & $6.35 \pm 1.3^{*}$ \\
\hline & $\mathrm{I} / \mathrm{R}$ & $7.06 \pm 0.67$ & $7.15 \pm 0.49$ & $7 \pm 0.59$ & $7 \pm 0.68$ & $7.27 \pm 0.93$ \\
\hline & $\mathrm{I} / \mathrm{R}+\mathrm{DMT}$ & $8.88 \pm 0.51$ & $8.55 \pm 0.91$ & $8.29 \pm 0.79$ & $8.51 \pm 0.61$ & $9.21 \pm 0.67^{\#,+}$ \\
\hline \multirow[t]{3}{*}{ Hct $[\%]$} & Control & $46.12 \pm 3.74$ & $44.42 \pm 5.61$ & $44.02 \pm 4.76$ & $43.85 \pm 4.92$ & $39.3 \pm 8.42^{*}$ \\
\hline & $\mathrm{I} / \mathrm{R}$ & $42.92 \pm 3.87$ & $43.99 \pm 2.46$ & $41.69 \pm 7.77$ & $42.97 \pm 3.96$ & $45.12 \pm 6.04^{\#}$ \\
\hline & $\mathrm{I} / \mathrm{R}+\mathrm{DMT}$ & $51.17 \pm 2.68$ & $49.48 \pm 5.56$ & $48.05 \pm 4.08$ & $49.65 \pm 3.02$ & $52.04 \pm 3.39^{\#+}$ \\
\hline \multirow[t]{3}{*}{$\mathrm{Hgb}[\mathrm{g} / \mathrm{dl}]$} & Control & $15.15 \pm 1.04$ & $14.5 \pm 1.69$ & $14.37 \pm 1.34$ & $14.16 \pm 1.55$ & $12.41 \pm 2.26^{*}$ \\
\hline & $\mathrm{I} / \mathrm{R}$ & $13.96 \pm 1.5$ & $14.25 \pm 0.79$ & $14.05 \pm 0.96$ & $13.95 \pm 1.3$ & $14.34 \pm 1.85^{\#}$ \\
\hline & $\mathrm{I} / \mathrm{R}+\mathrm{DMT}$ & $16.17 \pm 0.95$ & $15.61 \pm 1.71$ & $15.25 \pm 1.44$ & $15.48 \pm 0.85$ & $16.7 \pm 1.23^{\#,+}$ \\
\hline \multirow[t]{3}{*}{$\operatorname{MCV}[\mathrm{fl}]$} & Control & $60.27 \pm 1.26$ & $60.54 \pm 1.3$ & $60.81 \pm 1.51$ & $60.94 \pm 1.38$ & $61.73 \pm 0.86$ \\
\hline & $\mathrm{I} / \mathrm{R}$ & $60.78 \pm 1.67$ & $61.56 \pm 1.47$ & $61.72 \pm 1.75$ & $61.42 \pm 1.86$ & $62.1 \pm 1.92$ \\
\hline & $\mathrm{I} / \mathrm{R}+\mathrm{DMT}$ & $57.66 \pm 1.4$ & $58.85 \pm 1.18$ & $58.03 \pm 0.97$ & $58.41 \pm 1.03$ & $58.08 \pm 1.55$ \\
\hline \multirow[t]{3}{*}{ MCH [pg] } & Control & $19.82 \pm 0.64$ & $19.81 \pm 0.62$ & $19.89 \pm 0.52$ & $19.68 \pm 0.45$ & $19.63 \pm 0.64$ \\
\hline & $\mathrm{I} / \mathrm{R}$ & $19.8 \pm 1.12$ & $19.96 \pm 0.82$ & $20.44 \pm 1.64$ & $19.94 \pm 0.87$ & $19.74 \pm 0.75$ \\
\hline & $\mathrm{I} / \mathrm{R}+\mathrm{DMT}$ & $18.22 \pm 0.48$ & $18.26 \pm 0.42$ & $18.4 \pm 0.76$ & $18.22 \pm 0.56$ & $18.13 \pm 0.49$ \\
\hline \multirow[t]{3}{*}{$\mathrm{MCHC}[\mathrm{g} / \mathrm{dl}]$} & Control & $32.89 \pm 0.65$ & $32.68 \pm 0.57$ & $32.71 \pm 0.87$ & $32.33 \pm 0.42$ & $31.85 \pm 1.23$ \\
\hline & $\mathrm{I} / \mathrm{R}$ & $32.47 \pm 1.84$ & $32.41 \pm 0.91$ & $33.18 \pm 2.54$ & $32.47 \pm 0.54$ & $31.81 \pm 0.71$ \\
\hline & $\mathrm{I} / \mathrm{R}+\mathrm{DMT}$ & $31.61 \pm 0.69$ & $31.56 \pm 0.29$ & $31.75 \pm 1.06$ & $31.21 \pm 0.67$ & $31.23 \pm 0.72$ \\
\hline \multirow[t]{3}{*}{ WBC [G/l] } & Control & $4.59 \pm 1.37$ & $4.81 \pm 1.84$ & $5.03 \pm 0.76$ & $5.24 \pm 1.49$ & $4.96 \pm 0.88$ \\
\hline & $\mathrm{I} / \mathrm{R}$ & $5.42 \pm 1.59$ & $6.82 \pm 2.29^{*, \#}$ & $6.47 \pm 2.53$ & $6.17 \pm 3.17$ & $3.95 \pm 1.58^{*}$ \\
\hline & $\mathrm{I} / \mathrm{R}+\mathrm{DMT}$ & $5.05 \pm 0.86$ & $4.71 \pm 1.51^{+}$ & $5.1 \pm 1.93$ & $5.43 \pm 2.32$ & $5.02 \pm 2.5$ \\
\hline \multirow[t]{3}{*}{ Plt [G/l] } & Control & $916.8 \pm 233$ & $1039.2 \pm 144.1$ & $1060.1 \pm 125.3$ & $1028.4 \pm 133$ & $576.2 \pm 237.8$ \\
\hline & $\mathrm{I} / \mathrm{R}$ & $748.1 \pm 213.1$ & $958.7 \pm 138.4^{*}$ & $967.2 \pm 88.3^{*}$ & $868 \pm 230.1$ & $814.1 \pm 146.6$ \\
\hline & $\mathrm{I} / \mathrm{R}+\mathrm{DMT}$ & $794.7 \pm 125.9$ & $729 \pm 91.7^{\#,+}$ & $749.5 \pm 89.3^{\#,+}$ & $714.1 \pm .133 .6^{\#}$ & $748 \pm 181.7$ \\
\hline
\end{tabular}

means \pm S.D., ${ }^{*} p<0.05$ vs. Base; ${ }^{\#} p<0.05$ vs. Control; ${ }^{+} p<0.05$ vs. I/R. 
corpuscular volume, mean corpuscular hemoglobin, and mean corpuscular hemoglobin concentration did not show important alterations during the reperfusion period.

Total white blood cell count (WBC [G/l]) was stable in Control group. In I/R group an initial rise was observed after the ischemic period when both kidneys were clamped ( $p=0.032 \mathrm{vs}$. base, $p=0.016$ vs. Control, and $p=0.019$ vs. I/R+DMT), and afterwards it remained elevated and 120 minute after reperfusion we found a drop in the values ( $p=0.013$ vs. base). In I/R+DMT group the values were similar to the Control group. Platelet count showed a slight increase in Control group, ended in a drop by the 120 th minute ( $p=0.056$ vs. base). In I/R group platelet count (Plt [G/l]) moderately but significantly increased 30 minutes ( $p<0.001$ vs. base) and 60 minutes $(p<0.001$ vs. base) after starting the reperfusion. In I/R+DMT group a mild decreased was found (at I-60: $p<0.001 \mathrm{vs.} \mathrm{Control} \mathrm{and}$ I/R, at R-30: $p<0.001$ vs. Control and I/R, at R-60: $p<0.001$ vs. Control).

\subsection{Metabolic parameters}

Table 2 summarizes the changes in metabolic parameters. Blood $\mathrm{pH}$ slightly decreased in Control group and more in I/R group by the end of the experiment, and in I/R+DMT group it moderately increased ( $p=0.029$ vs. base). While the $\mathrm{pO}_{2}$ decreased in Control and $\mathrm{I} / \mathrm{R}$ groups 120 minutes after starting the reperfusion, it remained constant in I/R+DMT group (at R-120: $p=0.013$ vs. Control). The $p \mathrm{CO}_{2}$ values decreased in all groups by the 120 th minute of reperfusion (I/R: $p=0.05$ vs. base, I/R+DMT: $p<0.001$ vs. base). Bicarbonate concentration decreased by the 120 th minute of the reperfusion in all groups (Control: $p=0.002$ vs. base) and most expressedly in I/R ( $p<0.001$ vs. base, and $p=0.07$ vs. Control) and in I/R+DMT groups ( $p<0.001$ vs. base). Base excess decreased in Control group, but remained positive ( $p=0.003$ vs. base). In I/R group the decrease was large, became

Table 2

Changes of metabolic parameters in the Control, Ischemia-Reperfusion (I/R) and DMT-treated Ischemia-Reperfusion groups $(\mathrm{I} / \mathrm{R}+\mathrm{DMT})$

\begin{tabular}{|c|c|c|c|c|c|c|}
\hline Variable & Group & Base & $\mathrm{R}-120$ & Variable & Base & $\mathrm{R}-120$ \\
\hline \multirow[t]{3}{*}{$\mathrm{pH}$} & Control & $7.42 \pm 0.02$ & $7.37 \pm 0.35$ & lactate $[\mathrm{mmol} / 1]$ & $1.33 \pm 0.71$ & $1.72 \pm 0.76$ \\
\hline & $\mathrm{I} / \mathrm{R}$ & $7.4 \pm 0.06$ & $7.27 \pm 0.28$ & & $1.09 \pm 0.58$ & $2.37 \pm 0.7^{*}$ \\
\hline & $\mathrm{I} / \mathrm{R}+\mathrm{DMT}$ & $7.34 \pm 0.03$ & $7.36 \pm 0.15^{*}$ & & $1.19 \pm 0.89$ & $1.69 \pm 0.64^{*}$ \\
\hline \multirow[t]{3}{*}{$p \mathrm{O}_{2}[\mathrm{mmHg}]$} & Control & $98.45 \pm 8.21$ & $84.5 \pm 13.77$ & glucose $[\mathrm{mmol} / \mathrm{l}]$ & $8.63 \pm 1.21$ & $7.97 \pm 3.23$ \\
\hline & $\mathrm{I} / \mathrm{R}$ & $99.51 \pm 14.98$ & $90.22 \pm 20.1$ & & $8.21 \pm 0.99$ & $7.7 \pm 6.03$ \\
\hline & $\mathrm{I} / \mathrm{R}+\mathrm{DMT}$ & $102.39 \pm 4.72$ & $102.36 \pm 7.18^{\#}$ & & $9.78 \pm 1.39$ & $6.97 \pm 3.32^{*}$ \\
\hline \multirow{3}{*}{$p \mathrm{CO}_{2}[\mathrm{mmHg}]$} & Control & $45.9 \pm 4.19$ & $34.12 \pm 14.2$ & $\mathrm{Na}^{+}[\mathrm{mmol} / \mathrm{l}]$ & $139.33 \pm 0.81$ & $139 \pm 1.15$ \\
\hline & $\mathrm{I} / \mathrm{R}$ & $48.76 \pm 10.57$ & $35.67 \pm 12.68^{*}$ & & $135.27 \pm 8.69$ & $134.37 \pm 11.84$ \\
\hline & $\mathrm{I} / \mathrm{R}+\mathrm{DMT}$ & $50.71 \pm 6.73$ & $31.18 \pm 4.98^{*}$ & & $140 \pm 1.56$ & $140.62 \pm 2.02$ \\
\hline \multirow[t]{3}{*}{$\mathrm{cHCO}_{3}{ }^{-}[\mathrm{mmol} / \mathrm{l}]$} & Control & $29.76 \pm 1.58$ & $23.6 \pm 3.2^{*}$ & $\mathrm{~K}^{+}[\mathrm{mmol} / \mathrm{l}]$ & $4.35 \pm 0.2$ & $5.5 \pm 0.29^{*}$ \\
\hline & $\mathrm{I} / \mathrm{R}$ & $29.64 \pm 2.46$ & $16.78 \pm 6.39^{*}$ & & $4.23 \pm 0.33$ & $6.3 \pm 1.86^{*}$ \\
\hline & $\mathrm{I} / \mathrm{R}+\mathrm{DMT}$ & $28.92 \pm 2.71$ & $19.92 \pm 2.74^{*}$ & & $4.15 \pm 0.3$ & $4.65 \pm 0.55^{*, \#,+}$ \\
\hline \multirow[t]{3}{*}{$\mathrm{BE}(\mathrm{ecf})[\mathrm{mmol} / \mathrm{l}]$} & Control & $5.33 \pm 1.46$ & $\begin{array}{c}1.16 \pm 1.67^{*} \\
\left(1.96 \pm 0.55^{*}\right)\end{array}$ & $\mathrm{Ca}^{2+}[\mathrm{mmol} / \mathrm{l}]$ & $1.41 \pm 0.04$ & $1.25 \pm 0.07^{*}$ \\
\hline & $\mathrm{I} / \mathrm{R}$ & $4.83 \pm 1.5$ & $\begin{array}{c}-10 \pm 10.31^{*} \\
(10.7 \pm 9.48)\end{array}$ & & $1.4 \pm 0.04$ & $1.23 \pm 0.08^{*}$ \\
\hline & $\mathrm{I} / \mathrm{R}+\mathrm{DMT}$ & $4.05 \pm 1.26$ & $\begin{array}{l}-4.64 \pm 2.79^{*, \#} \\
(4.64 \pm 2.79)\end{array}$ & & $1.33 \pm 0.05$ & $1.16 \pm 0.04^{*, t}$ \\
\hline
\end{tabular}

means \pm S.D., BE data in italics $=$ absolute values, ${ }^{*} p<0.05$ vs. Base; ${ }^{\#} p<0.05$ vs. Control; ${ }^{+} p<0.05$ vs. I/R. 
negative ( $p<0.001$ vs. base, and $p=0.06$ vs. Control). In $/ \mathrm{R}+\mathrm{DMT}$ group negative $\mathrm{BE}$ was found as well ( $p<0.001$ vs. base and $p=0.005$ vs. Control).

Blood lactate concentration in parallel to $\mathrm{pH}$ markedly increased by the end of the observed reperfusion period in all groups. In Control group the change was not significant, but in I/R, where the largest rise was found ( $p<0.001$ vs. base) and in the I/R+DMT group ( $p=0.045$ vs. base), where a smaller increase was observed, the changes reached the level of significance. In I/R+DMT group there was a significant decrease in the glucose concentration ( $p=0.045 \mathrm{vs}$. base) that was not found in other groups. $\mathrm{Na}^{+}$concentration was stable in all groups, while we found an increase in $\mathrm{K}^{+}$concentration, which was the most expressed in I/R group (Control: $p<0.001$ vs. base, I/R: $p=0.003$ vs. base, I/R+DMT: $p=0.033$ vs. base, $p=0.022$ vs. Control and $p=0.045$ vs. I/R). $\mathrm{Ca}^{2+}$ showed a mild, but significant decrease in all groups (Control: $p=0.002$ vs. base, I/R: $p<0.001$ vs. base, I/R+DMT: $p<0.001$ vs. base, $p=0.35$ vs. Control).

\subsection{Red blood cell deformability}

Figure 1 shows the comparative parameters of the elongation index-shear stress curves. Elongation index values at a shear stress of $3 \mathrm{~Pa}$ have not changed in the Control group. In I/R group values were lower compared to the Control at the end of the bilateral renal ischemia $(p=0.007)$, in the 30th minute $(p=0.035)$ and in the 60th minute of the unilateral renal reperfusion, as the lowest values $(p=0.002$, and $p=0.028$ vs. base). Values of the $\mathrm{I} / \mathrm{R}+\mathrm{DMT}$ group were higher at these time points than those of the I/R group (at I-60: $p=0.039$, at R-30: $p=0.003$, at R-60: $p<0.001$ and at R-120: $p=0.001$ ) (Fig. 1A).

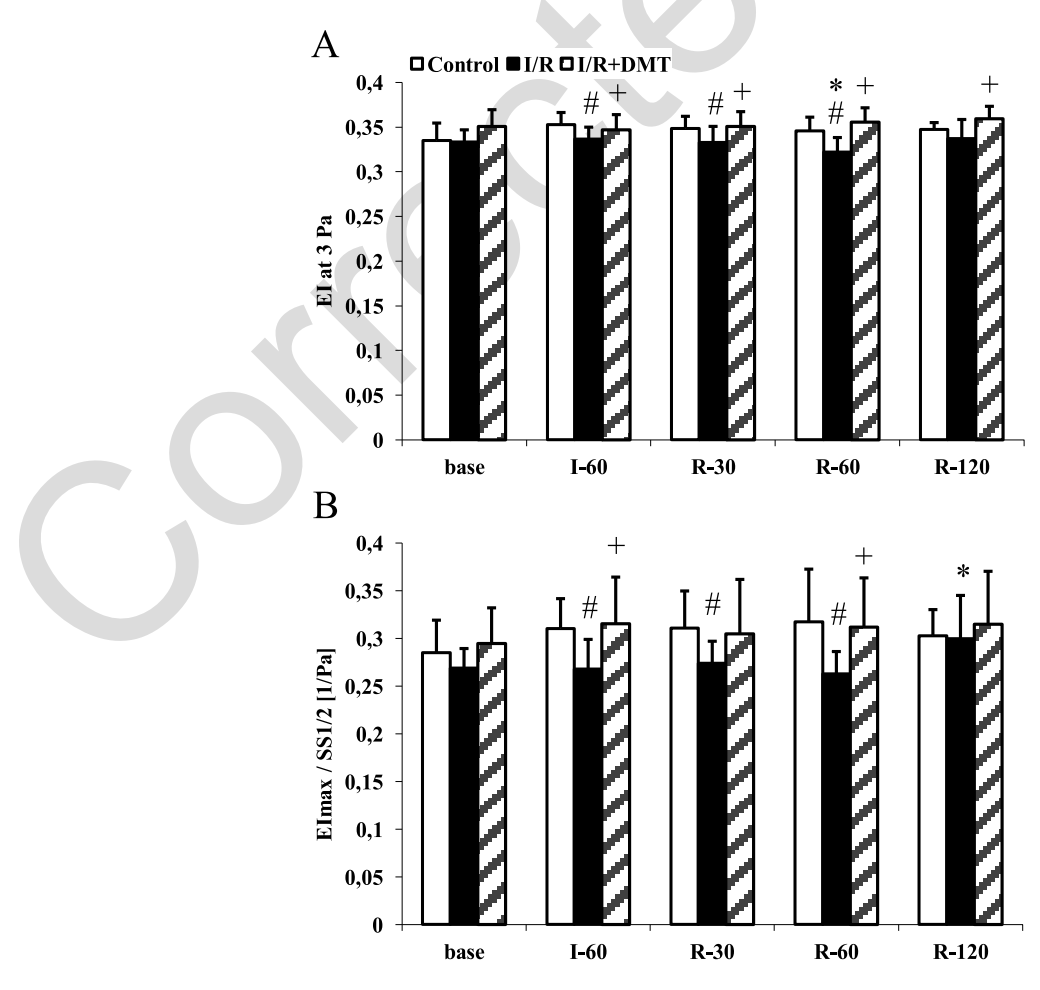

Fig. 1. Changes of the red blood cell deformability: elongation index at $3 \mathrm{~Pa}$ values (A) and $\mathrm{EI}_{\max } / \mathrm{SS}_{1 / 2}(\mathrm{~B})$ in the Control, Ischemia-Reperfusion (I/R) and DMT-treated Ischemia-Reperfusion groups (I/R+DMT) during the 120-minute reperfusion period after 60 -minute of kidney ischemia. means \pm S.D., ${ }^{*} p<0.05$ vs. Base; ${ }^{\#} p<0.05$ vs. Control; $+p<0.05$ vs. I/R. 
The $\mathrm{EI}_{\mathrm{max}} / \mathrm{SS}_{1 / 2}$ values $\left[\mathrm{Pa}^{-1}\right]$ calculated from the EI-SS curves showed the lowest values in the I/R group (at I-60 $p=0.008$ vs. Control and $p<0.001$ vs. I/R+DMT group, at R-30: $p=0.004$ vs. Control, at R-60: $p=0.008$ vs. Control and $p<0.001 \mathrm{cs}$. I/R-DMT group, and at R-120: $p=0.011$ vs. base) (Fig. 1B).

\subsection{Red blood cell aggregation}

Table 3 summarizes the values of the four aggregation indices. Figure 2A-D shows the values related to their base.

M $5 \mathrm{~s}$ values showed an initial rise in all groups versus their base (Control: $p<0.001, \mathrm{I} / \mathrm{R}: p=0.055$, I/R+DMT: $p=0.003$ ). In Control the values remained elevated (at R-30: $p=0.009$, at R-60: $p<0.001$ vs. base), and by the end of the 120-minute reperfusion they normalized. In I/R group the values decreased, while in the I/R+DMT group further increase was seen (R-30: $p<0.001$ vs. base, $p=0.011$ vs. Control, $p<0.001$ vs. I/R group; at R-60 $p<0.001$ vs. base, $p=0.036$ vs. Control, $p<0.001$ vs. I/R group; and at R-120: $p=0.019$ vs. base). The relative values (compared to their base) reflected these changes, the rise by the end of the ischemic period (Control: $p=0.004, \mathrm{I} / \mathrm{R}: p=0.034$ and I/R+DMT: $p=0.026$ vs. base), and the elevated values in Control (R-30: $p=0.002$, R-60: $p=0.004$ vs. base) and I/R+DMT group (R-30: $p=0.026, \mathrm{R}-60: p=0.037$ vs. base) (Fig. 2A).

M1 $5 \mathrm{~s}$ values has changed by time both in the I/R and the I/R+DMT groups. In the I/R group a decrease at R-30 was observed ( $p=0.044$ vs. Control), and in the $\mathrm{I} / \mathrm{R}+\mathrm{DMT}$ group a moderate increase

A
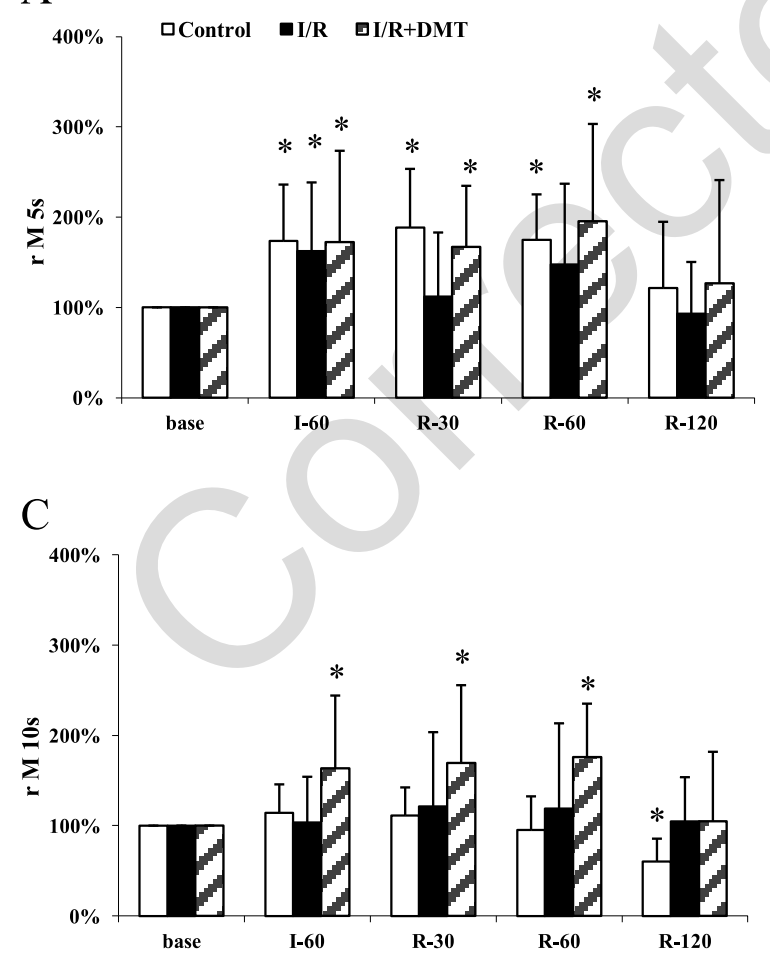

B

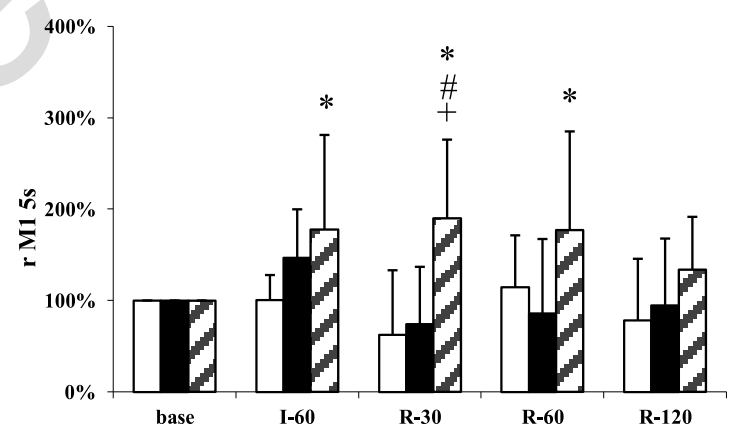

$\mathrm{D}$

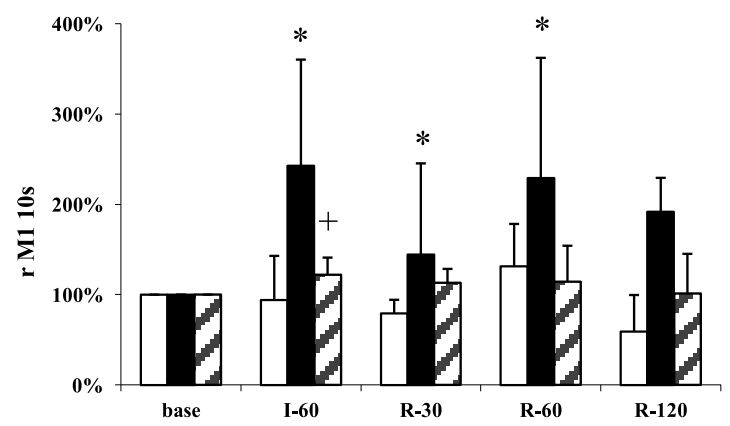

Fig. 2. Changes of the red blood cell aggregation index data related to their base values (rM $5 \mathrm{~s}, \mathrm{rM} 15 \mathrm{~s}$, rM $10 \mathrm{~s}$ and rM1 $10 \mathrm{~s})$ (A-D) in the Control, Ischemia-Reperfusion (I/R) and DMT-treated Ischemia-Reperfusion groups (I/R+DMT) during the 120 -minute reperfusion period after 60 -minute of kidney ischemia. means \pm S.D., ${ }^{*} p<0.05$ vs. Base; ${ }^{\#} p<0.05$ vs. Control; ${ }^{+} p<0.05$ vs. I/R. 
Table 3

Changes of aggregation indices (M 5 s, M1 5 s, M $10 \mathrm{~s}$ and M1 $10 \mathrm{~s}$ ) in the Control, Ischemia-Reperfusion (I/R) and DMT-treated Ischemia-Reperfusion groups (I/R+DMT)

\begin{tabular}{lcccccc}
\hline Index & Group & Base & I-60 & R-30 & R-60 & R-120 \\
\hline M 5s & Control & $3.49 \pm 1.42$ & $5.25 \pm 1.05^{*}$ & $4.77 \pm 1.51^{*}$ & $4.95 \pm 1.32^{*}$ & $3.59 \pm 2.25$ \\
& I/R & $3.13 \pm 1.31$ & $4.26 \pm 1.87^{*}$ & $3.65 \pm 1.75$ & $3.35 \pm 1.57$ & $2.72 \pm 1.29$ \\
& I/R+DMT & $3.41 \pm 1.84$ & $4.69 \pm 1.78^{*}$ & $6.01 \pm 1.91^{*, \#,+}$ & $5.83 \pm 1.63^{*, \#,+}$ & $4.55 \pm 1.92^{*}$ \\
M1 5s & Control & $3.56 \pm 1.13$ & $3.18 \pm 1.15$ & $3.42 \pm 1.71$ & $3.05 \pm 1.36$ & $3.2 \pm 1.82$ \\
& I/R & $3.49 \pm 1.47$ & $4 \pm 1.5$ & $2.62 \pm 1.89^{\#}$ & $3.52 \pm 2.78$ & $3.31 \pm 1.4$ \\
& I/R+DMT & $2.93 \pm 1.29$ & $3.79 \pm 1.32$ & $4.42 \pm 1.88^{+}$ & $4.38 \pm 1.21$ & $4.14 \pm 1.66$ \\
M 10s & Control & $14.25 \pm 3.91$ & $14.14 \pm 3.51$ & $13.31 \pm 3.15$ & $10.98 \pm 3.24^{*}$ & $9.45 \pm 3.68^{*}$ \\
& I/R & $8.17 \pm 4.71$ & $10.11 \pm 5.57^{\#}$ & $7.73 \pm 3.87^{\#}$ & $9.32 \pm 4.07$ & $7.4 \pm 4.65$ \\
& I/R+DMT & $8.33 \pm 4.09$ & $11.99 \pm 5.32$ & $15.91 \pm 3.44^{\#,+}$ & $13.22 \pm 4.63$ & $12.96 \pm 4.05$ \\
M1 10s & Control & $10.61 \pm 3.48$ & $9.32 \pm 3.82$ & $8.77 \pm 3.58$ & $11.36 \pm 3.7$ & $7.43 \pm 2.85^{*}$ \\
& I/R & $6.95 \pm 3.93$ & $9.34 \pm 3.82^{*}$ & $7.67 \pm 4.43$ & $7.65 \pm 3.95$ & $7.72 \pm 3.43$ \\
& I/R+DMT & $8.21 \pm 3.29$ & $9.95 \pm 3.15^{*}$ & $10.57 \pm 3.29^{*}$ & $10.6 \pm 4.51$ & $8.93 \pm 4.11$ \\
\hline
\end{tabular}

means \pm S.D.,${ }^{*} p<0.05$ vs. Base; ${ }^{\#} p<0.05$ vs. Control; ${ }^{+} p<0.05$ vs. I/R.

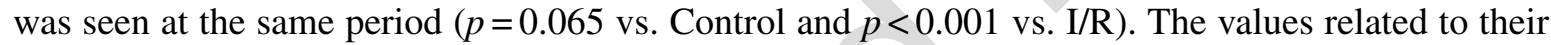
base showed the largest rise in the I/R+DMT group (at I-60: $p=0.038$ vs. base; at R-30: $p=0.04$ vs. base, $p=0.041$ vs. Control, $p=0.015$ vs. I/R, and at R-60: $p=0.047$ vs. base) (Fig. $2 \mathrm{~B}$ ).

M $10 \mathrm{~s}$ values continuously decreased in the Control group, reaching significant level by the 60th minute ( $p=0.003$ vs. base) and the 120th minute of the reperfusion ( $p<0.001$ vs. base). Values increased in the I/R group at I-60 ( $p=0.006$ vs. Control) and at R-30 ( $p<0.001$ vs. Control) time points. The rise in $\mathrm{I} / \mathrm{R}+\mathrm{DMT}$ group started later, showing a peak at $\mathrm{R}-30$ ( $p=0.012 \mathrm{vs}$. Control, $p=0.041 \mathrm{vs}$. I/R). The values related to the base showed increased level in the I/R+DMT group (I-60: $p=0.031$, R-30: $p=0.01$, R-60: $p=0.01$ vs. base) (Fig. 2C).

M 10 s values continuously decreased in the Control groups, reaching significant level by the 60th minute ( $p=0.003$ vs. base) and the 120th minute of the reperfusion ( $p<0.001$ vs. base). Values increased in the I/R group at I-60 ( $p=0.006$ vs. Control) and at R-30 ( $p<0.001$ vs. Control) time points. The rise in $\mathrm{I} / \mathrm{R}+\mathrm{DMT}$ group started later, showing a peak at R-30 ( $p=0.012$ vs. Control, $p=0.041 \mathrm{vs}$. I/R).

The same tendency was seen in the absolute values of the M1 $10 \mathrm{~s}$ index: decrease in the Control group (at R-120: $p=0.01$ vs. base), and rise in the I/R group at I-60 (I/R: $p=0.028$ vs. base, I/R-DMT: $p=0.013$ vs. base), at R-30 (I/R-DMT: $p=0.03$ vs. base) and at R-60 (I/R-DMT: $p=0.065$ vs. base) time points. When analyzing the relative values, a dominant rise only in the I/R group was seen (at I-60: $p=0.012$ vs. base and $p=0.029$ vs. I/R+DMT group, at R-30: $p=0.008$ vs. base, and at R-60: $p=0.05$ vs. base) (Fig. 2D).

\section{Discussion}

Transplantation is the only definitive treatment for patients with end stage kidney disease. Despite the progress both in anti-rejection treatment, preventive therapies and surgical technique, delayed graft function and acute rejection still remains a main problem [2-4, 24]. The transplanted kidney may be affected by ischemia reperfusion injury at various stages of transplantation. Warm ischemia already occurs during organ retrieval (from either a cadaveric or non-heart-beating donor), and as a second 
exposure during implantation until the vascular reperfusion. Allograft kidneys are exposed to cold ischemia during storage. When blood flow starts again, further harm shows up [5, 6].

In our study the alterations of hematological and micro-rheological parameters were investigated during 60-minute ischemia of both kidneys, followed by unilateral nephrectomy and 120-minute reperfusion of the remnant contralateral kidney. The model enables the investigation of ischemia-reperfusion injury occurring during kidney transplantation.

The whole process has been studied extensively, but the hemorheological changes have not been completely elucidated yet. Several authors agree that ischemia-reperfusion may influence the microrheological parameters such as red blood cell aggregation and deformability [12-14]. The changes are due to free radicals, inflammatory processes and metabolic changes. Free radicals damage the membrane of the red blood cells, the transmembrane and structural proteins and the haemoglobin molecule. Leukocyte activation as part of the inflammatory process may also contribute to oxidative stress. Decrease in ATP levels and calcium accumulation turn red blood cells' shape into echinocyte and sphero-echinocyte forms, while in decrease of $\mathrm{pH}$ stomatocyte or sphero-stomatocyte forms may appear. These alterations result in worsened micro-rheological parameters [13, 25-28].

In our study hematocrit and red blood cell count were significantly elevated during the reperfusion, accompanied by a decrease in $\mathrm{pH}$ and increased lactate level. These changes may be associated with the ischemia-reperfusion induced oxidative stress, inflammation and acute phase reactions. These processes affected different molecules, structures and cells, including erythrocytes that resulted in worsened micro-rheological parameters such as deterioration in red blood cell deformability and enhancement in aggregation [13, 14, 26].

There are only very few data about hemorheological changes in kidney ischemia-reperfusion in contrast to other organs such as heart, lungs, liver and bowels. In a 2011 study of Du and al. [29] about the hemorheological changes in patients with living-donor renal transplantation the blood viscosity and the erythrocyte aggregation decreased while the erythrocyte deformation index and the integrated deformation index had a remarkable improvement compared to pre-operation. They also found a decrease in the osmotic fragility of red blood cells after renal transplantation. These findings show the importance of hemorheological parameters by improving the organ microcirculation, therefore reducing the ischemia-reperfusion injury in the graft [29].

To prevent the damage various attempts have been done including the use of drugs, perfusion solutions and (re)perfusion methods [30-33]. As inflammation is seriously involved in I/R process, any agent that suppress inflammation process may be suitable to attenuate I/R injury. Several agents have been demonstrated to protect I/R injury having anti-inflammatory properties through various pathways. One of them is nicotine, a cholinergic agonist that protects renal function by suppressing neutrophil infiltration, chemokin release and inflammation [30, 31]. Celastrol, a bioactive ingredient of the Chinese medicinal herb, Thunder God Vine, was reported to ameliorate I/R-induced kidney injury by preventing the expression of pro-inflammatory mediators [32].

A recent study has demonstrated that dimethyltryptamines act not only as neuromodulators or psychedelics, but are also important regulators of both innate and adaptive immunity. They are potent anti-inflammatory agents, which have the capacity to modulate the functional activities of human dendritic cells via sigma-1-receptor. Based on the opinion of the authors "DMT sigma-1 axis emerges as a promising candidate for novel pharmacotherapies of chronic inflammatory and autoimmune diseases" [20].

We wondered if DMT can reduce the damage caused by I/R based on its antiinflammatory effect. No literature data were found about the administration of this drug in this context. It was found that administration of this drug before ischemia and before the restart of the circulation effectively reduced the harm caused by I/R concerning the alterations in the micro-rheological changes. The findings on red blood cell aggregation are controversial (Table 3, Fig. 2). The effect was different on the four 
index parameters. It is supposed that the dynamics of the aggregation might have been altered. The light-transmission techniques provide a "cross-section" of the process at the 5th or the 10th second of the aggregation at zero or at very low $\left(3 \mathrm{~s}^{-1}\right)$ shear rate. Due to the limitation of the blood sample volumes, we could not investigate the aggregation by syllectometry, which requires about $1 \mathrm{ml}$ of blood per test, and by which method we would see more on the earlier seconds of the aggregation [21]. The issue is interesting, because in a previous study we have found that the aggregation half-time values in the rats are very low, suggesting that the aggregation process is fast [34].

\section{Conclusion}

We found that metabolic and micro-rheological parameters impair after 60-minute of (bilateral) renal ischemia and during the (unilateral) reperfusion. N,N-dimethyl-tryptamine DMT could reduce but not completely prevent the changes (lactate, $\mathrm{pH}$, electrolytes, red blood cell deformability and aggregation in this rat model.

\section{Acknowledgments}

The authors are grateful for the technical staff of the Department of Operative Techniques and Surgical Research, Faculty of Medicine, University of Debrecen.

The authors comply with the Ethical Guidelines for Publication in Clinical Hemorheology and Microcirculation as published on the IOS Press website and in Volume 63, 2016, pp. 1-2. of this journal.

\section{References}

[1] Chatterjee PK. Novel pharmacological approaches to the treatment of renal ischemia-reperfusion injury: A comprehensive review. Naunyn Schmiedebergs Arch Pharmacol. 2007;376(1-2):1-43.

[2] Tilney NL, Guttmann RD. Effects of initial ischemia/reperfusion injury on the transplanted kidney. Transplantation. 1997;64(7):945-7.

[3] Requião-Moura LR, Durão Junior Mde S, Matos AC, Pacheco-Silva A. Ischemia and reperfusion injury in renal transplantation: Hemodynamic and immunological paradigms. 2015;13(1):129-35. doi: 10.1590/S1679-45082015RW3161.

[4] Bonventre JV, Yang L. Cellular pathophysiology of ischemic acute kidney injury. J Clin Invest. 2011;121(11):4210-21.

[5] Eltzschig H, Eckle T. Ischemia and reperfusion - from mechanism to translation. Nat Med. 2011;17(11):1391-401. doi: 10.1038/nm.2507

[6] Nemeth N, Toth E, Nemes B. Agents targeting ischemia-reperfusion injury. In: Huifang C, Shiguang Q, editors. Current Immunosuppressive Therapy in Organ Transplantation. New York: Nova Science Publishers; 2015. pp. 487-33.

[7] Bulkley GB. Free radical-mediated reperfusion injury: A selective review. Br J Cancer Suppl. 1987;8:66-73.

[8] Carden DL, Granger DN. Pathophysiology of ischaemia-reperfusion injury. J Pathol. 2000;190(3):255-66.

[9] Braun D, Dietze S, Pahlitzsch TMJ, Wennysia IC, Persson PB, Ludwig M, Patzak A. Short-term hypoxia and vasa recta function in kidney slices. Clin Hemorheol Microcirc. 2017. doi: 10.3233/CH-179230. [Epub ahead of print]

[10] Vollmar B, Menger MD. Intestinal ischemia/reperfusion: Microcirculatory pathology and functional consequences. Langenbecks Arch Surg. 2011;396(1):13-29. doi: 10.1007/s00423-010-0727-x

[11] Doi K, Rabb H. Impact of acute kidney injury on distant organ function:recent findings and potential therapeutic targets. Kidney Int. 2016;89(3):555-64. doi: 10.1016/j.

[12] Kayar E, Mat F, Meiselman HJ, Baskurt OK. Red blood cell rheological alterations in a rat model of ischemia-reperfusion injury. Biorheology. 2001;38(5-6):405-14.

[13] Baskurt OK. Mechanism of blood rheology alterations. In: Baskurt OK, Hardeman MR, Rampling MW, Meiselman HJ, editors. Handbook of Hemorheology and Hemodynamics. Amsterdam: IOS Press; 2007. pp. 170-90.

[14] Nemeth N, Furka I, Miko I. Hemorheological changes in ischemia-reperfusion: An overview on our experimental surgical data. Clin Hemorheol Microcirc. 2014;57(3):215-25. doi: 10.3233/CH-131648 
[15] Lipowsky HH. Microvascular rheology and hemodynamics. Microcirculation. 2005;12(1):5-15. doi: 10.1080/10739680 590894966

[16] Popel AS, Johnson PC. Microcirculation and hemorheology. Annu Rev Fluid Mech. 2005;37:43-69. doi: 10.1146/annurev.fluid.37.042604.13393

[17] Jung F, Mrowietz C, Hiebl B, Franke RP, Pindur G, Sternitzky R. Influence of rheological parameters on the velocity of erythrocytes passing nailfold capillaries in humans. Clin Hemorheol Microcirc. 2011;48(1):129-39. doi: 10.3233/CH2011-1392

[18] Malek M, Nematbakhsh M. Renal ischemia/reperfusion injury; from pathophysiology to treatment. Renal Inj Prev. 2015;4(2):20-7. doi: 10.12861/jrip.2015.06

[19] Saat TC, van den Akker EK, Ijzermans JN, Dor FJ, de Bruin RW. Improving the outcome of kidney transplantation by ameliorating renal ischemia reperfusion injury: Lost in translation? J Transl Med. 2016;14:20. doi:10.1186/s12967016-0767-2

[20] Szabo A, Kovacs A, Frecska E, Rajnavolgyi E. Psychedelic N,N-dimethyltryptamine and 5-methoxy-N,Ndimethyltryptamine modulate innate and adaptive inflammatory responses through the sigma-1 receptor of human monocyte-derived dendritic cells. PLoS One. 2014;9(8):e106533. doi:10.1371/journal.pone.0106533

[21] Hardeman MR, Goedhart PT, Shin S. Methods in hemorheology. In: Baskurt OK, Hardeman MR, Rampling MW, Meiselman HJ, editors. Handbook of Hemorheology and Hemodynamics. Amsterdam: IOS Press; 2007. pp. $242-66$.

[22] Baskurt OK, Meiselman HJ. Data reduction methods for ektacytometry in clinical hemorheology. Clin Hemorheol. Microcirc. 2013;54:99-107.

[23] Schmid-Schönbein H, Malotta H, Striesow F. Erythrocyte aggregation: Causes, consequences and methods for assessment. Tijdschr NVKC. 1990;15:88-97.

[24] Jassem W, Fuggle SV, Rela M, Koo DD, Heaton ND. The role of mitochondria in ischemia/reperfusion injury. Transplantation. 2002;73(4):493-9.

[25] Reinhart WH, Chien S. Red cell rheology in stomatocyte-echinocyte transformation: Roles of cell geometry and cell shape. Blood. 1980;67:1110-8.

[26] Baskurt OK, Temiz A, Meiselman HJ. Effect of superoxide anions on red blood cell rheologic properties. Free Radic Biol Med. 1998;24(1):102-10. doi: 10.1016/S0891-5849(97)00169-X

[27] Nemeth N, Miko I, Furka A, Kiss F, Furka I. Concerning the importance of changes in hemorheological parameters caused by acid-base and blood gas alterations in experimental surgical models. Clin Hemorheol Microcirc. 2012;51(1):43-50. doi: 10.3233/CH-2011-1507

[28] Grau M, Kollikowski A, Bloch W. Remote ischemia preconditioning increases red blood cell deformability through red blood cell-nitric oxide synthase activation. Clin Hemorheol Microcirc. 2016;63(3):185-97. doi: 10.3233/CH-152039

[29] Du Y, Yao W, Qian Y, Han M, Wen Z, Ma L. Hemorheological changes in patients with living-donor renal transplantation. Clin Hemorheol Microcirc. 2011;47(3):199-209. doi: 10.3233/CH-2010-1381

[30] Sadis C, Teske G, Stokman G, Kubjak C, Claessen N, Moore F, Loi P, Diallo B, Barvais L, Goldman M, Florquin S, Le Moine A. Nicotine protects kidney from renal ischemia/reperfusion injury through the cholinergic anti-inflammatory pathway. PLoS One. 2007;2:e469.

[31] Yeboah M, Xue X, Duan B, Ochani M, Tracey K, Susin M, Metz CN. Cholinergic agonists attenuate renal ischemia-reperfusion injury in rats. Kidney Int. 2008;74:62-9.

[32] Chu C, He W, Kuang Y, Ren K, Gou X. Celastrol protects kidney against ischemia-reperfusion-induced injury in rats. J Surg Res. 2014;186:398-407.

[33] Kenyeres P, Sinay L, Jancso G, Rabai M, Toth A, Toth K, Arato E. Controlled reperfusion reduces hemorheological alterations in a porcine infrarenal aortic-clamping ischemia-reperfusion model. Clin Hemorheol Microcirc. 2016;63(3):235-43. doi: 10.3233/CH-162059

[34] Kiss F, Toth E, Peto K, Miko I, Nemeth N. The investigation of interspecies diversity of erythrocyte aggregation properties by two different photometric methods in four animal species. J Anim Physiol Anim Nutr (Berl). 2015;99(6):1074-83. doi: 10.1111/jpn.12301 